\title{
Analisis Interferensi White Space Device terhadap Sistem Radio Navigasi Penerbangan pada Frekuensi $960 \mathrm{MHz}$
}

\author{
LYDIA SARI, SYAH ALAM, INDRA SURJATI
}

\author{
Teknik Elektro Universitas Trisakti \\ Email: lydia_sari@trisakti.ac.id
}

Received 10 Januari 2019 | Revised 29 Januari 2019 | Accepted 4 April 2019

\begin{abstract}
ABSTRAK
Pemerintah Indonesia mengalokasikan spektrum frekuensi 960-1164 MHZ untuk sistem komunikasi bergerak maupun untuk radio navigasi penerbangan. Penggunaan White Space Device (WSD) merupakan solusi keterbatasan spektrum, karena mampu mengidentifikasi dan memanfaatkan frekuensi yang tidak terpakai. Penelitian ini menyelidiki potensi interferensi yang terjadi pada koeksistensi sistem radio navigasi penerbangan serta perangkat WSD di pita 960 MHz. Penelitian menggunakan pendekatan matematis Minimum Coupling Loss (MCL) serta simulasi dengan Spectrum Engineering Advanced Monte Carlo Analysis Tool (SEAMCAT). Hasil penelitian menunjukkan bahwa level interferensi yang masih diperbolehkan berada di kisaran $-81,589$ dBm. Level ini tercapai dengan penggunaan jarak proteksi antar sistem sejauh $36 \mathrm{~km}$. Penurunan daya pemancar WSD atau peningkatan gain RSBN sebesar $1 \mathrm{dBm}$ dapat memperkecil jarak proteksi menjadi $30 \mathrm{~km}$ untuk mencapai probabilitas interferensi berturutturut $3,55 \%$ dan $3,6 \%$.
\end{abstract}

Kata kunci: white space devices, interferensi, radio navigasi penerbangan

\begin{abstract}
The Indonesian Government allocates the 960-1164 MHz spectrum for mobile communications and aeronautical radio navigation services. Cognitive radio is a technology which will enable the use of a limited spectrum optimally. Devices implemented with cognitive radio capability is referred as White Space Device (WSD) as they can identify and utilize idle channels. This paper investigates the interference potential between aeronautical radio navigation services and WSD as they co-exist in the $960 \mathrm{MHz}$ spectrum using Minimum Coupling Loss (MCL) formulae and simulations using Spectrum Engineering Advanced Monte Carlo Analysis Tool (SEAMCAT). Results show that the permissible interference level is $-81,589 \mathrm{dBm}$ which is achievable if the two systems are separated by $36 \mathrm{~km}$. Decreasing the WSD power level or increasing the RSBN gain by $1 \mathrm{dBm}$ can decrease the protection distance between the two systems to $30 \mathrm{~km}$ to achieve an interference probability of 3,55\% and 3,6\%, respectively.
\end{abstract}

Keywords: white space devices, interference, aeronautical radio navigation 


\section{PENDAhULUAN}

Jumlah perangkat nirkabel berdaya tinggi yang semakin banyak telah meningkatkan kebutuhan akan spektrum radio, yang merupakan sumberdaya yang terbatas. Namun demikian eksperimen oleh Federation Communications Commission menunjukkan bahwa $80 \%$ hingga $90 \%$ spektrum terlisensi tidak digunakan secara penuh (Attapatu, Tellambura, \& Jiang, 2014).

Teknologi cognitive radio dipandang sebagai solusi potensial untuk mengatasi permasalahan tersebut karena kemampuannya untuk mengidentifikasi frekuensi yang tidak terpakai (white space), dan memanfaatkan frekuensi tersebut untuk memberikan layanan kepada pengguna. Lebih jauh lagi, cognitive radio transceiver memiliki spectrum intelligence, yang dapat diartikan sebagai kemampuan untuk mempelajari lingkungan spektrum dan mengadaptasi parameter-parameter transmisi sesuai lingkungan spektrum. Dengan kemampuannya memanfaatkan white spaces, perangkat dengan teknologi cognitive radio dikenal juga sebagai White Space Device (WSD).

Untuk mengubah parameter transmisi termasuk frekuensi operasi, cognitive radio memiliki kemampuan Dynamic Spectrum Access (DSA) (Huang, Liu, \& Ding, 2009; Lin, Liu, \& Hsieh, 2013). DSA dapat diaplikasikan pada jaringan cognitive radio yang memiliki struktur akses hierarkhis dengan pengguna terlisensi (pengguna primer) dan pengguna tidak terlisensi (pengguna sekunder). Tujuan utama dari DSA adalah membuka spektrum terlisensi kepada pengguna sekunder, tanpa menimbulkan interferensi yang bermakna pada pengguna primer (Attapatu, Tellambura, \& Jiang, 2014).

Di masa mendatang, integrasi WSD dengan sistem seluler nirkabel maupun sistem komunikasi lainnya sangat dimungkinkan. Dengan demikian, potensi interferensi antara sistem WSD dengan sistem lainnya pada pita frekuensi tertentu perlu diteliti. Pita 960-1164 $\mathrm{MHz}$ di Indonesia dialokasikan untuk sistem komunikasi bergerak maupun untuk sistem radio navigasi penerbangan (Kementerian Informasi dan Komunikasi RI, 2017). Sistem radio navigasi penerbangan pada pita tersebut terdiri atas radio system of short-range navigation (RSBN), radar sekunder untuk Air Traffic Control (ATC) termasuk radar terrestrial dan pemancar pada pesawat udara, serta radar utama airfield dan rute untuk ATC (Direkur Jenderal Perhubungan Udara RI, 2017). Kebutuhan akan spektrum frekuensi aeronautikal sangat tinggi dan krusial bagi penerbangan, terutama dengan semakin padatnya lalu lintas angkutan udara serta implementasi teknologi baru (Jacob, Sirigina, Madhukumar, \& Prasad, 2016). Secara khusus RSBN pada pita 960 dan $1215 \mathrm{MHz}$ digunakan di Indonesia untuk keperluan Distance Measuring Equipment (DME) pada sistem radio navigasi penerbangan. Teknologi DME mengukur jarak antara pesawat dan ground station dengan menghitung waktu tunda propagasi dari sinyal radio pada pita frekuensi di antara 960 dan $1215 \mathrm{MHz}$. Awak pesawat akan memulai perhitungan dengan mengirimkan pulse pair pada frekuensi carrier dan alokasi kanal tertentu pada transponder ground station. Setelah waktu tunda tertentu, transponder merespon dengan mengirimkan pulse pair pada frekuensi yang terpisah dari frekuensi yang digunakan oleh pesawat sejauh $63 \mathrm{MHz}$. Sistem DME terdiri atas pemancar dan penerima UHF sebagai interrogator atau inisiator pengukuran jarak yang berada di pesawat, serta pemancar dan penerima UHF di bagian ground station.

Penelitian mengenai potensi interferensi pada sistem radio navigasi penerbangan telah dilakukan untuk frekuensi 694-790 MHz (Ancans, Stankevicius, Bobrovs, \& Ivanovs, 2016; Stankevicius \& Oberauskas, 2014). Pada kedua penelitian tersebut, pita frekuensi yang diteliti adalah pita yang telah dialokasikan untuk layanan komunikasi bergerak dan juga digunakan untuk sistem radio navigasi penerbangan pada ITU Region 1 dimana 
Eropa termasuk di dalamnya. Model propagasi yang digunakan pada kedua penelitian tersebut adalah ITU-R P.1546 yaitu model yang digunakan pada sistem broadcasting. Hasil dari kedua penelitian tersebut menyatakan diperlukan jarak pisah sejauh $132 \mathrm{~km}$ antara sistem seluler dengan sistem radio navigasi penerbangan, untuk menekan potensi inteferensi.

Penelitian ini bertujuan menyelidiki potensi interferensi pada sistem radio navigasi penerbangan di Indonesia yang bekerja pada frekuensi $960 \mathrm{MHz}$, akibat adanya transmisi $\mathrm{co}^{-}$ channe/ dari sistem seluler yang memiliki kemampuan cognitive radio. Hal ini terkait dengan adanya alokasi frekuensi yang berdekatan untuk sistem radio navigasi penerbangan di Indonesia yaitu pada frekuensi $960-1215 \mathrm{MHz}$ dan untuk sistem bergerak seluler pada frekuensi 890 - $960 \mathrm{MHz}$ (Kementerian Informasi dan Komunikasi RI, 2017). Pada saat ini, perangkat bergerak seluler masih belum berupa cognitive radio. Namun perkembangan teknologi masa mendatang sangat memungkinkan perangkat memiliki kemampuan tersebut. Dengan demikian dimungkinkan perangkat seluler bergerak masa depan merupakan WSD yang mampu mengindera spektrum yang idle serta memanfaatkan spektrum tersebut untuk bertransmisi (Zhang, Zhang, Xiao, \& Yu, 2015; Reddy \& Lakshmi, 2014). Hal ini berpotensi menimbulkan interferensi antar sistem yang menggunakan frekuensi yang bersisian, karena kemampuan penginderaan spektrum yang tidak sempurna.

Pada penelitian ini digunakan pendekatan matematis dengan metode Minimum Coupling Loss (MCL) untuk menentukan jarak pisah optimum antara kedua sistem agar tidak terjadi interferensi. Selain itu dilakukan pula simulasi Monte Carlo menggunakan peranti lunak Spectrum Engineering Advanced Monte Carlo Analysis Tool (SEAMCAT) untuk menentukan probabilitas inteferensi yang terjadi sebagai fungsi jarak antar sistem.

Bagian kedua dari makalah ini memaparkan metodologi penelitian, yaitu pendekatan dengan $\mathrm{MCL}$, simulasi dengan SEAMCAT, parameter-parameter yang digunakan serta skenario interferensi. Bagian ketiga menyajikan hasil dan analisis dari perhitungan dan simulasi, serta analisis pengaruh dari penurunan daya BTS WSD dan peningkatan gain sistem RSBN terhadap probabilitas interferensi. Kesimpulan disampaikan pada bagian terakhir.

\section{METODOLOGI ANALISIS POTENSI INTERFERENSI}

\subsection{Metode MCL}

MCL adalah salah satu metode yang dapat digunakan untuk menentukan separasi frekuensi antara dua sistem yang beroperasi pada kanal yang sama atau bersebelahan. Perhitungan menggunakan metode $\mathrm{MCL}$ menghasilkan nilai isolasi dalam $\mathrm{dB}$, yang dapat dikonversi menjadi jarak pemisah antar sistem bila digunakan rumus pathloss yang sesuai (European Radiocommunications Committee, 1999). Metode ini sederhana dan akan memberikan hasil perhitungan yang sesuai untuk skenario worst-case, namun tidak efisien secara sepektral.

Pada penelitian ini, sistem yang terkena interferensi (victim link) adalah RSBN dan sinyal penginterferensi adalah transmisi bergerak seluler downlink. Sinyal yang ditransmisikan WSD BTS dan menginterferensi sistem WSD dinyatakan sebagai Inteference Received Signal Strength (iRSS), sedangkan sinyal downlink yang ditujukan kepada WSD user equipment dinyatakan sebagai Desired Received Signal Strength (dRSS). Skenario interferensi diilustrasikan pada Gambar 1. 


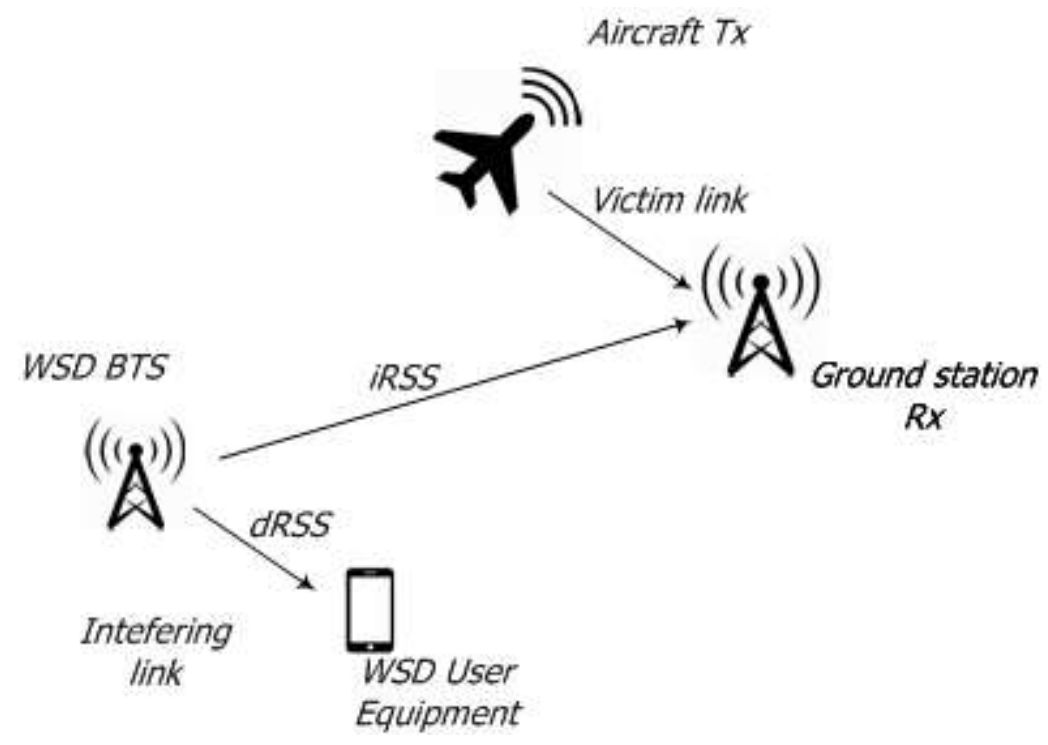

\section{Gambar 1. Skenario Interferensi}

Model propagasi yang digunakan pada victim link adalah ITU-R P.1546 (International Telecommunication Union, 2013). Model ini digunakan untuk layanan broadcasting atau terrestrial lainnya, terutama untuk kasus-kasus dimana terdapat posisi antena pemancar yang sangat tinggi, yaitu di atas 60 meter. Dengan demikian, model ini sesuai untuk penelitian ini, dimana terdapat aircraft transmitter. Untuk interfering link digunakan model propagasi Okumura-Hatta, sebuah model propagasi yang tidak hanya tergantung pada jarak namun juga pada parameter eksternal lainnya di lingkungan urban (Molisch, 2011). Lingkungan urban adalah kondisi tipikal dimana layanan telekomunikasi bergerak nirkabel diimplementasikan, dimana perangkat telepon genggam dibawa berpindah-pindah pada lingkungan yang dipenuhi penghalang (cluttered). Model Okumura-Hata juga digunakan pada jalur propagasi antara WSD BTS ke penerima RSBN.

Untuk melakukan perhitungan dengan metode $\mathrm{MCL}$, diperlukan perhitungan pathloss terlebih dahulu. Model Okumura-Hata diberikan oleh (Molisch, 2011)

$$
P L=A+B \log (d)+C
$$

dimana $P L$ menotasikan pathloss sedangkan $A, B$, dan $C$ adalah faktor-faktor yang tergantung pada frekuensi dan tinggi antena. Faktor $A, B$, dan $C$ adalah sebagai berikut:

$$
\begin{gathered}
A=69,55+26,16 \log (f)-13,82 \log \left(h_{t x}\right)-a\left(h_{r x}\right) \\
B=44,9-6,55 \log \left(h_{t x}\right)
\end{gathered}
$$

dimana $h_{t x}$ dan $h_{r x}$ berturut-turut adalah tinggi antena pemancar dan antena penerima dalam meter, $f$ adalah frekuensi dalam $\mathrm{MHz}$ dan $d$ adalah jarak dalam $\mathrm{km}$. Fungsi $a\left(h_{r x}\right)$ serta koefisien $C$ untuk daerah urban adalah

$$
\begin{gathered}
a\left(h_{r x}\right)=(1,1 \log (f)-0,7) h_{t x}-(1,56 \log (f)-0,8) \\
C=0
\end{gathered}
$$


Analisis Interferensi White Space Devices terhadap Sistem Radio Navigasi Penerbangan pada Frekuensi $960 \mathrm{MHz}$

Untuk daerah sub-urban digunakan

$$
C=-2 \log (f / 28)^{2}-5,4
$$

Untuk daerah sub-urban, $a\left(h_{r x}\right)$ ditentukan menggunakan Persamaan (4).

RSBN pada frekuensi $960 \mathrm{MHz}$ merupakan sistem radio navigasi jarak pendek. Stasiun pemancar berupa aircraft transmitter yang mentransmisikan sinyal pulsa untuk range request dan indication response (International Telecommunication Union, 2010). Stasiun penerima adalah stasiun bumi baik yang terdapat di bandara maupun di sepanjang jalur penerbangan. Parameter RSBN yang digunakan pada penelitian ini diberikan pada Tabel 1.

Tabel 1. Karakteristik RSBN (link radio dari aircraft ke ground) (Electronic Communications Committee, 2013; International Telecommunication Union, 2010)

\begin{tabular}{|l|c|}
\hline \multicolumn{1}{|c|}{ Parameter } & Nilai \\
\hline Daya pemancar pulse $(\mathrm{dB})$ & 27 \\
\hline Tipe antenna & Omnidirectional \\
\hline Polarisasi antena pemancar & linear \\
\hline Antenna gain maximum $(\mathrm{dB})$ & 10 \\
\hline Ketinggian pemancar di atas tanah $(\mathrm{m})$ & 10 \\
\hline Ketinggian penerima $(\mathrm{m})$ & 10 \\
\hline Receiver passband $(\mathrm{MHz})$ & 22 \\
\hline Frekuensi penerima $(\mathrm{MHz})$ & 960 \\
\hline Sensitivitas penerima $(\mathrm{dB})$ & -125 \\
\hline Rasio proteksi $C / I(\mathrm{~dB})$ & 20 \\
\hline $\begin{array}{l}\text { Agregat field strength yang diperbolehkan untuk semua } \\
\text { bandwidth emisi, } \mathrm{dB}(\mu \mathrm{V} / \mathrm{m})\end{array}$ & 42 \\
\hline
\end{tabular}

Karakteristik WSD secara teoretis dapat diimplementasikan pada berbagai sistem telekomunikasi, namun dianjurkan untuk menggunakan model WSD yang dibedakan atas sistem outdoor atau sistem indoor (Electronic Communications Committee, 2013).

Parameter sistem outdoor diambil dari parameter sistem seluler yang telah diimplementasikan pada saat ini, sedangkan untuk sistem indoor digunakan parameter dari sistem komunikasi WiFi. Pada penelitian ini, digunakan model WSD outdoor dengan parameter dari sistem bergerak seluler. Hal ini dilakukan untuk menyesuaikan dengan skenario simulasi dimana jalur penginterferensi adalah dari base station bergerak seluler ke penerima RSBN (stasiun bumi). Parameter untuk WSD diberikan pada Tabel 2 dan Tabel 3.

Tabel 2. Karakteristik WSD (BTS)

\begin{tabular}{|l|c|}
\hline \multicolumn{1}{|c|}{ Parameter } & Nilai \\
\hline Frekuensi pemancar $(\mathrm{MHz})$ & 960 \\
\hline Frekuensi penerima $(\mathrm{MHz})$ & 915 \\
\hline Daya pemancar $(\mathrm{dBm})$ & 58 \\
\hline Tinggi antenna $(\mathrm{m})$ & 30 \\
\hline Densitas & 14 \\
\hline Antenna gain maximum $(\mathrm{dBi})$ & -6 \\
\hline Rasio proteksi $I / N(\mathrm{~dB})$ & 9 \\
\hline Bandwidth kanal $(\mathrm{MHz})$ & 2,05 per km2 (daerah urban) \\
\hline
\end{tabular}


Tabel 3. Karakteristik WSD (UE)

\begin{tabular}{|l|c|}
\hline \multicolumn{1}{|c|}{ Parameter } & Nilai \\
\hline Frekuensi pemancar $(\mathrm{MHz})$ & 915 \\
\hline Frekuensi penerima $(\mathrm{MHz})$ & 960 \\
\hline Bandwidth kanal $(\mathrm{MHz})$ & 10 \\
\hline EIRP $(\mathrm{dBm})$ & 23 \\
\hline Tinggi antenna $(\mathrm{m})$ & 1,5 \\
\hline Noise figure $(\mathrm{dB})$ & 9 \\
\hline
\end{tabular}

Jarak proteksi antara sistem RSBN dengan sistem WSD dapat dihitung menggunakan metode $\mathrm{MCL}$ dengan terlebih dahulu menentukan level daya penginterferensi yang diperbolehkan pada penerima RSBN, yaitu

$$
P_{\text {interferensi }}=P_{W S D_{-} B T S}+G_{R S B N}-(P L+I / N)
$$

dimana $P_{\text {WS_BST }}$ adalah daya pemancar WSD, GRSBN adalah gain antena WSD dan RSBN, $P L$ adalah pathloss dan I/Nadalah kriteria proteksi Interference to Noise.

\subsection{Simulasi dengan SEAMCAT}

Probabilitas terjadinya interferensi pada sistem victim dapat dihitung menggunakan peranti lunak SEAMCAT. SEAMCAT memungkinkan perhitungan secara statistik dengan skenario yang realistik, dimana kondisi kanal berubah-ubah sepanjang waktu sistem beroperasi (Electronic Communications Committee, 2016). Pada simulasi SEAMCAT dalam penelitian ini digunakan spectrum emission mask sesuai 3GPP TS 36.104 di sisi pemancar WSD, sebagaimana diilustrasikan pada Gambar 2.

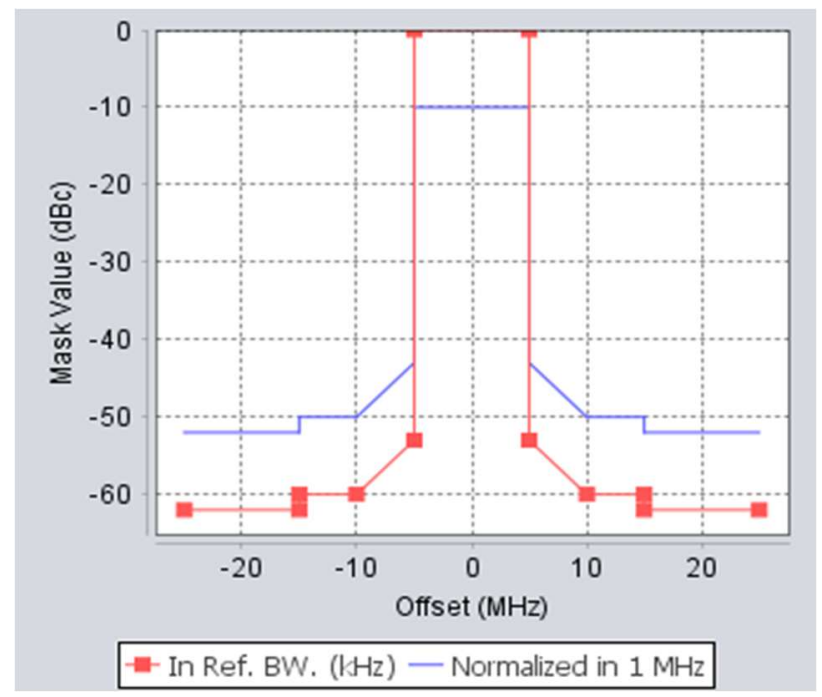

\section{Gambar 2. Spectrum Emission Mask pada Pemancar WSD}

WSD yang dimodelkan pada penelitian ini memiliki kemampuan DSA sehingga dapat memanfaatkan suatu pita frekuensi walaupun pada pita tersebut terdapat sistem lain yang beroperasi. Telah diketahui bahwa sistem telekomunikasi memiliki duty cycle tertentu sehingga terdapat waktu-waktu tertentu dimana tidak terjadi transmisi. Sebelum mengakses suatu pita frekuensi untuk bertransmisi, WSD harus memonitor kondisi pita frekuensi tersebut. Idealnya, WSD tidak melakukan transmisi saat ada sistem lain yang sedang bertransmisi pada pita frekuensi yang sama (Wyglinski, Nekovee, \& Hou, 2010). Salah 
satu cara untuk memonitor kondisi pita frekuensi adalah dengan melakukan sensing atau penginderaan berbasis energi (Arslan \& Yucek, 2007). Dengan sistem penginderaan ini, penerima WSD tidak memerlukan pengetahuan tentang sinyal primary user atau pengguna lain pada spektrum yang akan digunakan bersama. Sinyal dideteksi dengan membandingkan keluaran dari detektor energi terhadap suatu threshold yang tergantung pada noise floor. Sinyal terima dapat dinyatakan sebagai berikut

$$
y(n)=s(n)+w(n)
$$

dimana $s(n)$ adalah sinyal yang perlu dideteksi, $w(n)$ adalah sampel Additive White Gaussian Noise (AWGN) dan $n$ adalah indeks sampel. Metrik pengambilan keputusan mengenai ada atau tidaknya transmisi pada spektrum yang sedang diindera untuk penginderaan berbasis energi adalah

$$
M=\sum_{n=0}^{N}|y(n)|^{2}
$$

Sistem akan mengambil keputusan berupa hipotesis nol $\left(H_{0}\right)$ yaitu tidak terdapat sistem yang bertransmisi pada spektrum yang diindera, atau sebaliknya hipotesis alternatif $\left(H_{1}\right)$. Kedua hipotesis tersebut dapat dinyatakan sebagai berikut:

$$
\begin{aligned}
& H_{0}: y(n)=w(n) \\
& H_{1}: y(n)=s(n)+w(n)
\end{aligned}
$$

Sistem WSD dengan penginderaan berbasis energi dapat disimulasikan pada SEAMCAT dengan mengaktifkan button Cognitive Radio dan memasukkan parameter detection threshold, probabilitas kegagalan penginderaan, serta bandwidth reception penginderaan.

\section{HASIL DAN ANALISIS}

Menggunakan Persamaan (1)-(6) serta parameter-paramater pada Tabel 1-3, dapat diperoleh nilai level sinyal penginterferensi yang masih dapat diterima oleh penerima RSBN tanpa menimbulkan gangguan yang signifikan. Level penginterferensi tersebut dapat dikonversi menjadi jarak proteksi antara kedua sistem agar tidak terjadi interferensi yang signifikan pada penerima RSBN. Hasil perhitungan level sinyal penginterferensi yang diperbolehkan serta jarak proteksi antara kedua sistem diberikan pada Tabel 4, untuk daya pemancar BTS WSD sebesar $58 \mathrm{dBm}$.

Tabel 4. Level Inteferensi yang Diperbolehkan dan Jarak Proteksi Antar Sistem

\begin{tabular}{|c|c|c|}
\hline Lingkungan & Level Interferensi (dBm) & Jarak Proteksi $\mathbf{( k m )}$ \\
\hline Urban & $-81,589$ & 36 \\
\hline Sub-urban & $-101,55$ & 76 \\
\hline
\end{tabular}

Hasil perhitungan menunjukkan bahwa ko-eksistensi antara sistem WSD dan sistem RSBN dimungkinkan dengan jarak proteksi minimal $36 \mathrm{~km}$ untuk kondisi lingkungan urban. Pada daerah sub-urban, daerah line-of-sight akan lebih terbuka dibandingkan dengan lingkungan urban karena jumlah penghalang berupa bangunan yang lebih sedikit. Hal ini menyebabkan jarak proteksi antar sistem untuk daerah sub-urban harus lebih besar dibandingkan dengan jarak proteksi untuk daerah urban. 
Hasil simulasi menggunakan SEAMCAT dari scenario interferensi yang diilustrasikan pada Gambar 1 diberikan pada Tabel 5. Simulasi dibangkitkan sebanyak 20.000 kali pada frekuensi $960 \mathrm{MHz}$. Jarak antara sistem penginterferensi serta sistem yang terkena interferensi divariasikan antara $1 \mathrm{~km}$ hingga $35 \mathrm{~km}$. Nilai $d R S S$ adalah daya sinyal dari aircraft transmitter yang tiba di penerima RSBN, sehingga daya ini cenderung konstan karena dalam simulasi tidak terdapat perubahan jarak antara aircraft transmitter dengan penerima RSBN. Nilai iRSS adalah daya sinyal penginterferensi yang tiba di penerima RSBN. Semakin jauh posisi BTS penginterferensi dari penerima RSBN, nilai iRSS secara konsisten akan menurun.

Tabel 5. Probabilitas Interferensi pada Sistem RSBN, Daya BTS $=58 \mathrm{dBm}$

\begin{tabular}{|c|c|c|c|}
\hline $\begin{array}{c}\text { Jarak antara WSD BTS } \\
\text { dengan penerima } \\
\text { RSBN (km) }\end{array}$ & dRSS (dBm) & $\begin{array}{c}\text { iRSS Unwanted } \\
\mathbf{( d B m )}\end{array}$ & $\begin{array}{c}\text { Probabilitas } \\
\text { Interferensi (\%) }\end{array}$ \\
\hline 1 & $-40,64$ & $-23,62$ & 99,89 \\
\hline 5 & $-40,70$ & $-48,27$ & 88,11 \\
\hline 10 & $-40,69$ & $-58,91$ & 56,25 \\
\hline 15 & $-40,69$ & $-65,10$ & 33,49 \\
\hline 20 & $-40,72$ & $-69,42$ & 19,85 \\
\hline 25 & $-40,69$ & $-73,80$ & 10,49 \\
\hline 30 & $-40,69$ & $-77,35$ & 5,51 \\
\hline 35 & $-40,65$ & $-80,70$ & 2,73 \\
\hline
\end{tabular}

Dari hasil simulasi diketahui bahwa probabilitas interferensi baru akan berada di bawah angka $5 \%$ bila jarak antara WSD BTS dan penerima RSBN adalah di atas $30 \mathrm{~km}$. Level penginterferensi sebesar $-80,70 \mathrm{dBm}$ akan menghasilkan probabilitas interferensi $2,73 \%$. Nilai level penginterferensi tersebut cukup mendekati nilai hasil perhitungan dengan metode $\mathrm{MCL}$ untuk kondisi urban $(-81,589 \mathrm{dBm})$. Sesuai dengan hasil perhitungan dengan metode $\mathrm{MCL}$, jarak antara kedua sistem harus di atas $35 \mathrm{~km}$ untuk memperoleh probabilitas interferensi yang minimal.

Mengingat layanan telekomunikasi seluler memiliki jangkauan yang luas di daerah perkotaan, untuk memastikan kompatibilitas antar sistem seluler dengan RSBN di satu wilayah yang berdekatan diperlukan pengaturan daya pada sistem telekomunikasi seluler, atau gain antena sistem RSBN.

Hasil simulasi dengan penurunan daya BTS WSD menjadi $57 \mathrm{dBm}$ dengan parameter lainnya tidak berubah diberikan pada Tabel 6 .

Tabel 6. Probabilitas Interferensi pada Sistem RSBN, Daya BTS $=57 \mathrm{dBm}$

\begin{tabular}{|c|c|c|c|}
\hline $\begin{array}{c}\text { Jarak antara WSD BTS } \\
\text { dengan penerima } \\
\text { RSBN (km) }\end{array}$ & dRSS (dBm) & $\begin{array}{c}\text { iRSS Unwanted } \\
\mathbf{( d B m )}\end{array}$ & $\begin{array}{c}\text { Probabilitas } \\
\text { Interferensi (\%) }\end{array}$ \\
\hline 1 & $-40,68$ & $-25,78$ & 99,78 \\
\hline 5 & $-40,71$ & $-50,16$ & 84,32 \\
\hline 10 & $-40,68$ & $-60,87$ & 49,32 \\
\hline 15 & $-40,69$ & $-67,09$ & 26,93 \\
\hline 20 & $-40,66$ & $-71,45$ & 14,76 \\
\hline 25 & $-40,71$ & $-75,68$ & 7,23 \\
\hline 30 & $-40,73$ & $-79,44$ & 3,55 \\
\hline 35 & $-40,68$ & $-82,78$ & 1,52 \\
\hline
\end{tabular}


Dari hasil simulasi yang ditampilkan pada Tabel 6, tampak bahwa dengan penurunan daya BTS WSD sebesar $1 \mathrm{dBm}$, probabilitas interferensi dibawah 5\% dapat tercapai dengan jarak pisah antar sistem sejauh $30 \mathrm{~km}$. Perbandingan hasil simulasi pada Tabel 5 dan Tabel 6, menunjukkan bahwa penurunan daya BTS WSD dapat menurunkan probabilitas interferensi seperti disarikan pada Gambar 3.

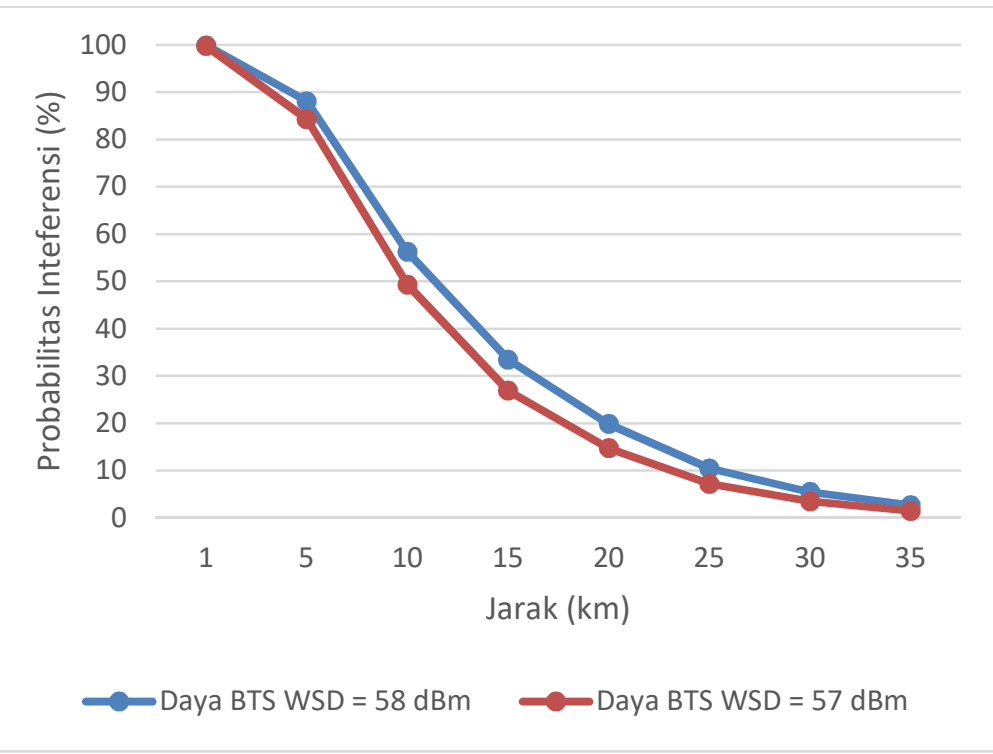

\section{Gambar 3. Pengaruh Penurunan Daya BTS WSD terhadap Probabilitas Interferensi}

Pengaturan di sisi RSBN dapat dilakukan dengan meningkatkan gain antena pemancar dan penerima. Tabel 7 memberikan hasil simulasi bila gain sistem RSBN baik di sisi pemancar maupun penerima dinaikkan menjadi $11 \mathrm{dBi}$. Daya pancar BTS WSD yang digunakan pada simulasi yang ditampilkan pada Tabel 7 adalah $58 \mathrm{dBm}$.

Tabel 7. Probabilitas Interferensi pada Sistem RSBN dengan Gain $11 \mathrm{dBi}$

\begin{tabular}{|c|c|c|c|}
\hline $\begin{array}{c}\text { Jarak antara WSD BTS } \\
\text { dengan penerima } \\
\text { RSBN (km) }\end{array}$ & dRSS (dBm) & $\begin{array}{c}\text { iRSS Unwanted } \\
\text { (dBm) }\end{array}$ & $\begin{array}{c}\text { Probabilitas } \\
\text { Interferensi (\%) }\end{array}$ \\
\hline 1 & $-42,71$ & $-27,66$ & 99,88 \\
\hline 5 & $-42,66$ & $-52,18$ & 84,39 \\
\hline 10 & $-42,68$ & $-62,93$ & 49,02 \\
\hline 15 & $-42,73$ & $-69,03$ & 27,16 \\
\hline 20 & $-42,67$ & $-73,42$ & 14,60 \\
\hline 25 & $-42,69$ & $-77,80$ & 7,14 \\
\hline 30 & $-42,73$ & $-81,40$ & 3,60 \\
\hline 35 & $-42,70$ & $-84,66$ & 1,83 \\
\hline
\end{tabular}

Perbandingan hasil simulasi yang diberikan pada Tabel 6 dan 7 menunjukkan bahwa penurunan daya BTS WSD sebesar $1 \mathrm{dBm}$ atau peningkatan gain sistem RSBN sebesar $1 \mathrm{dBi}$ akan menghasilkan probabilitas interferensi di bawah $5 \%$ pada jarak pemisah antar sistem sejauh $30 \mathrm{~km}$. Pengaruh peningkatan gain sistem RSBN terhadap probabilitas interferensi ditampilkan pada Gambar 4. 


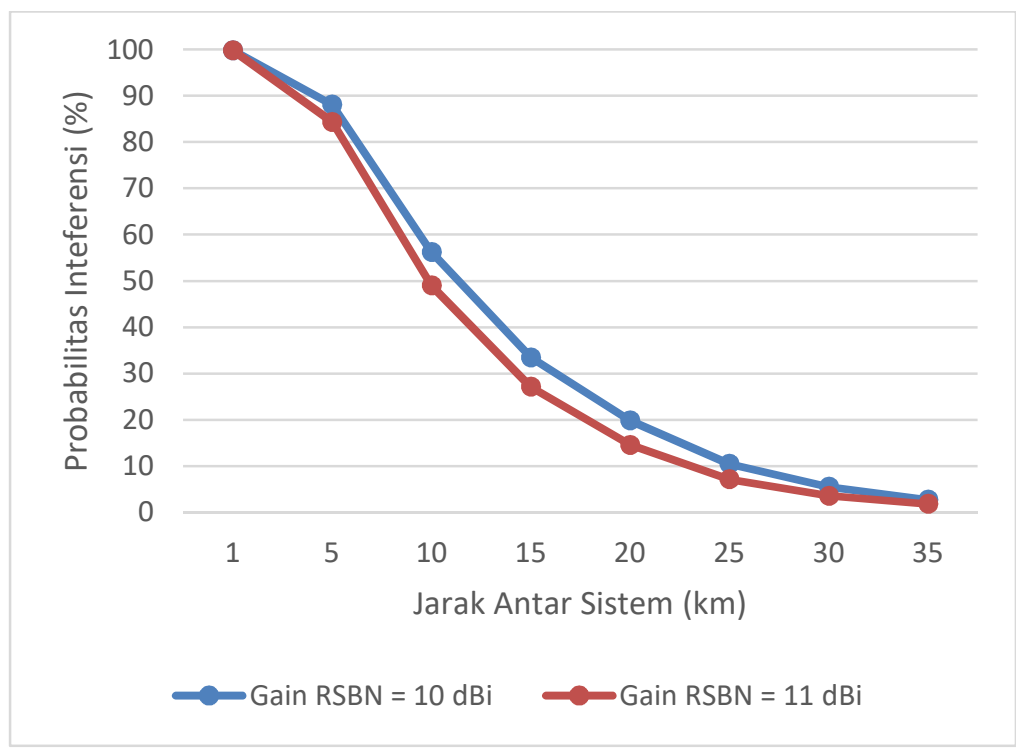

\section{Gambar 4. Pengaruh Peningkatan Gain RSBN terhadap Probabilitas Interferensi}

Baik hasil perhitungan maupun simulasi menunjukkan bahwa penggunaan WSD bergerak seluler di daerah perkotaan dimana terdapat sistem radio navigasi penerbangan harus diperhitungkan secara cermat karena besarnya probabilitas interferensi yang dapat terjadi.

\section{KESIMPULAN}

Potensi interferensi antara sistem WSD dan sistem radio navigasi penerbangan pada pita 960 $\mathrm{MHz}$ telah diteliti menggunakan metode perhitungan $\mathrm{MCL}$ serta simulasi menggunakan peranti lunak SEAMCAT. Sistem WSD berupa sistem bergerak seluler, sedangkan sistem radio navigasi penerbangan berupa radio system of short-range navigation (RSBN). Hasil perhitungan dengan metode MCL menunjukkan bahwa level penginterferensi yang masih diperbolehkan agar RSBN tidak terganggu adalah -81,589 dBm. Konversi level tersebut ke jarak proteksi menghasilkan jarak sejauh $36 \mathrm{~km}$ agar sistem WSD tidak menginterferensi sistem RSBN secara bermakna. Hasil simulasi dengan SEAMCAT menunjukkan bahwa level daya penginterferensi dapat mencapai $-80,70 \mathrm{dBm}$ bila kedua sistem dipisahkan dengan jarak sejauh $35 \mathrm{~km}$. Pada jarak tersebut, probabilitas terjadinya interferensi adalah 2,73\%. Penurunan probabilitas terjadinya interferensi antara kedua sistem dapat dicapai dengan menurunkan daya pemancar WSD atau menaikkan gain sistem RSBN. Simulasi untuk daya pemancar WSD sebesar $57 \mathrm{dBm}$ atau gain sistem RSBN sebesar $11 \mathrm{dBi}$ menunjukkan probabilitas interferensi berturut-turut sebesar 3,55\% dan 3,6\% dapat dicapai dengan jarak pemisah sejauh $30 \mathrm{~km}$. Dari hasil perhitungan dan simulasi diketahui bahwa probabilitas terjadinya interferensi pada sistem RSBN akibat dioperasikannya sistem WSD cukup bermakna. Untuk kondisi di Indonesia dimana pita $960 \mathrm{MHz}$ telah dialokasikan untuk sistem telekomunikasi bergerak serta sistem radio navigasi penerbangan, diperlukan penelitian lebih lanjut untuk memastikan kedua sistem dapat beroperasi tanpa interferensi yang bermakna. 
Analisis Interferensi White Space Devices terhadap Sistem Radio Navigasi Penerbangan pada Frekuensi $960 \mathrm{MHz}$

\section{DAFTAR RUJUKAN}

Ancans, G., Stankevicius, E., Bobrovs, V., \& Ivanovs, G. (2016). Evaluation of LTE and Aeronautical Radionavigation Service Electromagnetic Compatibility in $694-790 \mathrm{MHz}$ Frequency Band. Elektronika IR Electrotechnika, 22(6), 99-103.

Arslan, H., \& Yucek, T. (2007). Spectrum Sensing for Cognitive Radio Applications. In H. Arslan, Cognitive Radio, Software Defined Radio, and Adaptive Wireless System. Dordrecht: Springer.

Attapatu, S., Tellambura, C., \& Jiang, H. (2014). Energy Detection for Spectrum Sensing in Cognitive Radio. New York: Springer.

Direkur Jenderal Perhubungan Udara RI. (2017). Peraturan No. KP 110/2017 Tetang Pedoman Teknis Operasional Bagian 171-10 Tata Cara dan Prosedur Penggunaan Frekuensi Radio Untuk Kegiatan Penerbangan. Jakarta: Direkur Jenderal Perhubungan Udara RI.

Electronic Communications Committee. (2013). Report 185 Complementary Report to ECC Report 159 Further Definition of Technical and Operational Requirements for the Operation of White Space Devices in the Band 470-790 MHz. European Conference of Postal and Telecommunications Administrations (CEPT).

Electronic Communications Committee. (2016, April 29). Report 252 Seamcat Handbook Edition 2. Copenhagen: European Communications Office.

European Radiocommunications Committee. (1999). Report 101, A Comparison Of The Minimum Coupling Loss Method, Enhanced Minimum Coupling Loss Method, And The Monte-Carlo Simulation. Menton: European Conference of Postal and Telecommunications Administrations (CEPT).

Huang, S., Liu, X., \& Ding, Z. (2009). Optimal Transmission Strategies for Dynamic Spectrum Access in Cognitive Radio Networks. IEEE Transactions on Mobile Computing, 8(12), $1636-1648$.

International Telecommunication Union. (2010). Report ITU-R M.2205, Results of studies of the $A M(R) S$ allocation in the band 960-1164 MHz and of the AM(R)S allocation in the band 5030-5091 MHz to support control and non-payload communications links for unmanned aircraft systems. International Telecommunication Union.

International Telecommunication Union. (2013). Report ITU-R P.1546-5, Method for point-toarea predications for terrestrial services in the frequency range $30 \mathrm{MHz}$ to $3000 \mathrm{MHz}$. International Telecommunication Union. 
Jacob, P., Sirigina, R., Madhukumar, A., \& Prasad, V. (2016). Cognitive Radio for Aeronautical Communications: A Survey. IEEE Access, 4(1),3417-3443.

Kementerian Informasi dan Komunikasi RI. (2017). Tabel Alokasi Spektrum Radio di Indonesia. Jakarta: Kementerian Informasi dan Komunikasi RI.

Lin, Y., Liu, K., \& Hsieh, H. (2013). On Using Interference-Aware Spectrum Sensing for Dynamic Spectrum Access in Cognitive Radio Networks. IEEE Transactions on Mobile Computing , 12(3), 461-474.

Molisch, A. F. (2011). Wireless Communication. West Sussex: John Wiley \& Sons.

Reddy, B., \& Lakshmi, B. (2014). BER Analysis of Energy Detection Spectrum Sensing in Cognitive Radio Using GNU Radio. International Journal of Computer and Information Engineering, 8(11),1699-1705.

Stankevicius, E., \& Oberauskas, S. (2014). Electromagnetic Compatibility Studies: LTE BS vs Aeronautical Radionavigation Services in 694-790 MHz Frequency Band. De Gruyter Open on Electrical, Control and Communication Engineering, 6(1),38-44.

Wyglinski, A., Nekovee, M., \& Hou, Y. (2010). Cognitive Radio Communication and Networks Principal and Practice. San Diego: Academic Press.

Zhang, C., Zhang, Y., Xiao, J., \& Yu, J. (2015). Aeronautical Central Cognitive Broadband Airto-Ground Communications. IEEE Journal on Selected Areas in Communications, $33(5), 946-957$. 